\title{
Impact of Contextualized Text on Students' Learning of Writing Skills at Tertiary Level
}

\author{
Dr. Najeeb us Saqlain ${ }^{1}$ \\ Dr. Ismail $\mathrm{Saad}^{2}$ \\ Rafiq ul Islam ${ }^{3}$
}

\begin{abstract}
Contextualized text is the text resulting from the local circumstances and in accordance with learners' needs and cognition level. It also suggests that the text in use includes language, understandable to the target learners, and suits the philosophy and psychology of the learners and the society. Knowledge shifts from one context to another more successfully when the pupil understands not only the specific but also the generalized vision - the fundamental ideology, models, and associations attained through the application of comprehension. True experimental design is adopted for the research to explain the relationship between dependent and independent variables. Two groups (control and experimental) are selected randomly to conduct the experiment. The independent variable of the study is 'contextualized text' and dependent variable is 'writing skills' of the learners while learners' socioeconomic status is taken as an attribute variable. One public sector business school is selected randomly for the experiment from which 80 students were distributed in two groups as control and experimental groups with 40 students in each group through a process of randomization. Simple factorial design is selected to study the effects of attribute variable on the dependent variable. Descriptive statistics is used to convert the textual data into numerical one in order to make it measurable and statistically provable. ANOVA is used to draw inferences from the data obtained. The findings signify that improvement in students' learning is because of the treatment and their socioeconomic status has no effect on the improvement in performance of students.
\end{abstract}

\section{Keywords: Contextualized text, writing skills}

\section{Introduction}

English language has become a "lingua franca" and is widely used across the globe. Kameda (2001) suggests that English already has become a language spoken by so many people in so many places, as it is already observed, it is a language spoken by more people as a second tongue than the first (Kameda, 2001). In view of this explanation there are several languages which are performing this task but with some geographical limitations like Spanish between South America and parts of North America; French among Canada, some parts of Europe and some parts of Africa; Chinese in some parts of Asia. English is the only language which is being used as a means of communication irrespective of purpose and geographical limits all across the world. The majority of these countries uses English as official language, and consider it their second language (Morgan, 2001). In context of Pakistan, English Language has become inevitable and is considered as a yardstick to measure an individual's competence for success in his profession regardless of his field.

\footnotetext{
${ }^{1}$ Dr. Najeeb us Saqlain is Controller Examinations, Iqra University, Karachi, najeebsaqlain@hotmail.com

${ }^{2}$ Dr. Ismail Saad is Dean, Faculty of Education \& Learning Sciences, Iqra University, Karachi.

${ }^{3}$ Rafiq ul Islam is PhD Scholar, Iqra University, Karachi, rafiqulislamhyd@yahoo.com

\begin{tabular}{llll|l}
\hline JISR-MSSE & Volume 12 & Number 1 & January-June 2014 & 73
\end{tabular}
}


English Language has four basic skills. These skills are integrated out of which two are considered receptive skills and other two are considered as productive skills.

$$
\stackrel{\text { Receptive Skills }}{\longrightarrow}\left\{\begin{array}{c}
\text { Listening Skills } \\
\text { Reading Skills }
\end{array}\right\} \stackrel{\text { Productive Skills }}{\longrightarrow}\left\{\begin{array}{c}
\text { Speaking Skills } \\
\text { Writing Skills }
\end{array}\right\}
$$

The above-mentioned skills show that listening and speaking skills are connected together while reading and writing skills are mutually linked up. It also mentions receptive and productive skills. The study focuses on writing skills only at tertiary level of Pakistan. English language teaching has been an area of major concern among educators for many years now. The very concept of skill-based teaching itself is relatively new in the country. A handful of researchers are working on teaching methodologies and their effectiveness and impact on students' learning at different levels of education. Researchers in Pakistan have started working on skill-based teaching of English language and also skill-based testing. Yousuf (2012) suggests in his doctoral research about pivotal role of skill-oriented language teaching strategy in improving language learners' competency.

Teachers have been trying to come up with modern and effective strategies of teaching writing skills to the students coming from a variety of educational, social and economical backgrounds. These students lack pre-requisite skills and knowledge regarding the target skill. Also, books that are available and used for the purpose are non-contextualized; written by foreign writers. In order to develop competence and proficiency among students over business writing, understanding the scenario and cases that are presented to them becomes of utmost importance. Students do not seem to understand the information provided for business writing activities and as a result memorize the content. Many methods of English language teaching can be used for developing speaking skill one of these methods that is comparatively more modern in terms of time is Contextualized Teaching Learning (CTL). The purpose of the study is to document, explore and describe the impact of contextualized text on students' learning of writing skills at tertiary level.

Objectives of the study are to measure the relationship between contextualized text and students' writing skills. Also, to measure the relationship between students' socio-economic status and their writing skills by teaching through contextualized text. And to provide research in Pakistani context regarding learning of writing skills of English as a second language through contextualized text.

\section{Literature Review}

English for specific purpose (ESP) course design is usually based on the definite needs of learners of a particular discipline. There are different purpose-oriented ESP courses such as English for Academic Purposes, English for Engineering Purposes, English for Medical Purposes, English for Business Purposes and English for Tourism. Hutchinson and Waters (1987) mention that there are various successful occasions where ESP practitioners while designing a course conduct need analysis to find out learners' real needs before incorporating the course contents in the syllabus. English for Business Purposes, as obvious for its name, is that type of language that is particularly used in business setting. Different business

\begin{tabular}{l|llll}
\hline 74 & January-June 2014 & Volume 12 & Number 1 & JISR-MSSE
\end{tabular}


organizations may have different organization culture and methods of communication but one thing has become inevitable now and that is the language. Most of international trade is carried out and recorded in English Language. English for Business Purposes has its own vocabulary sometimes it become so technical that only a person having the relevant knowhow can understand them. Even in business, different aspects of business may have different vocabulary; for example in Business Finance, language used will be difficult even for a customary business graduate to understand. For that one has to be a finance graduate. Language for Business and Corporate Law would be more technical. Language for banking is different than marketing or advertising. All business graduates have to learn English for Business Purposes. According to Hutchinson and Waters (1987, p.19), "ESP came into being after the Second World War, which was the time of enormous and unprecedented expansion in scientific, technical and economic activity on an international scale". Another reason of ESP emerging as a sub-field of linguistics is advancement in linguistics. Linguistics concerns more about other technicalities of a language but many language experts also started working on actual usage of language for real-time communication. Hutchison and Waters (1987) also maintain that ESP becomes more important after the distinction between spoken and written English, which means that language is usually altered according to the specific usage. They also suggest that if situation in which a language is used changes adaptation of language accordingly becomes necessary. Dudley-Evans and St. John (1998) presented an adapted definition of the variable characteristics of ESP. ESP may be related to or designed for specific disciplines. ESP may use, in specific teaching situations, a different methodology from that of General English; ESP is likely to be designed for adult learners, either at a tertiary level institution or in a professional work situation. It could, however, be for learners at secondary school level. ESP is generally designed for intermediate or advanced students.

\subsection{Writing Skills in English Language}

Writing is considered as one of the most effective and continuous process of exploring effective ways of communication. Peyton and Tran (1993) maintain that even if the skill is difficult, adult learners will continue to learn as an effective mode of sharing thoughts and opinions. Proficiency in language is assumed as a key to successful communication. In the words of McKee (1939) language will successfully assist people in diverse activities, which involve communication, various types of dealings, or even writing Whether we are students or not, there is a need to use language aptly. He further suggests that the capacity to write efficiently is still significant despite of the dominant and incredible effects of technology on human activities (McKee, 1939). When talking about effects of technology on writing, one adverse effect on writing has been caused by text messaging. Many educators have charged this technology of being negative for writing. According to Dolch (1942), Children must spell if they are to write. When we write, we are actually writing down our thoughts. These thoughts are expressed using words, and these words need to be spelled appropriately. Therefore, writing would need appropriate spelling. Writing is one of the most important ways of communication. According to Shidle (1965), writing skills are needed everywhere. In his book The Art of Successful Communication, he states that almost every task, every work and every activity needs communication skills. These skills are required by all of us to connect and share our ideas and for this, best way is to communicate through writing. According to Quattrini (1985), writing is the best way of showing our feelings because writing is like "shaping" our thoughts which means use of appropriate and most suitable vocabulary

\begin{tabular}{llll|l}
\hline JISR-MSSE & Volume 12 & Number 1 & January-June 2014 & 75
\end{tabular} 
for communicating our thoughts. At another occasion Cruse (2000) suggests that the best way of giving meanings to our thoughts is words.

Most of students of English as Foreign Language (EFL) are not proficient in English because they are non-native speakers and, to their drawback, most often live in a non-English-speaking setting, making the practicing of their English challenging. Also, in many EFL surroundings, English is only used as a means of communication in the classroom where teaching and learning activities are held. Outside the classroom, English may not be used because the community does not speak the language. Another negative feature of EFL contexts is that the writing instructors may be local academics. These local academics may have graduated from either a local or abroad university. Therefore, as local instructors, they may use more L1 (first language) and "bookish language", speak English less assertively or provide less cultural information (Murcia, 2001). These unfavorable circumstances in the EFL context have contributed to the many challenges concerned with creating successful high-class EFL writing classes. In addition to these issues, the following factors also add to the intricacy of teaching writing in an EFL context: language difficulty, influence of L1 (first language), differences between L1 and L2, genuineness, diverse entry levels of students, class sizes, and cultural influence.

Writing in the first language is already challenging for many EFL students (Rivers, 1968). “...EFL writing students encounter even greater challenges if they are requested to produce a piece of writing in English because they need to express themselves with the syntactical and rhetorical devices of a language which they are still learning" (Zhu, 2002, p.94). Murcia (2001) states that "the ability to express one's ideas in writing in a second or foreign language and to do so with reasonable coherence and accuracy is a major achievement; many native speakers of English never truly master this skill" (p. 205). Anokye (2008) agrees, stating that "writing is unlike any other academic skills in the sense that it is not something that necessarily gets easier with time" (p. 65). Brown (2001), together with Richards and Renandya (2002) also support this claim because the skills concerned in writing are complex. The students, learning a second language (L2), have to assign their concentration to two different facets, namely the lower level skills such as spelling, punctuation, or word choice and the higher level skills such as planning, and organizing. The two aspects are similar to what McDonough and Shaw (2003) introduce concerning the levels of writing.

\subsection{Writing for Business}

Communication skills are required everywhere, may it be at workplace, at personal life. Only then it can benefit from our communication fully. Writing is the tool to send message effectively and precisely and with concreteness, especially writing skill is a must of all managerial skills. It has been a common observation that most of the working professionals in a workforce in general lack writing skills. This shortcoming keeps them unstable and less confident when they come to their profession and start writing reports and other genre of the same sort. This becomes a major handicap in the way of their success and progress in reaching top management level. Though professional writing needs experience and practice as well but without getting to know the fundamentals of writing, only experience does not bring laurels. Through written communication one does not only get messages but it develops one's own writing skills too. According to Gerard (2008), "the objective of communication is not the transmission but the reception." One of the basic reasons of business writing is to request or receive information

\begin{tabular}{l|llll}
76 & January-June 2014 & Volume 12 & Number 1 & JISR-MSSE
\end{tabular}


or send information in form of letters, memos, reports and proposals. For business writing, one needs to learn with accuracy, conciseness and completeness. Purpose of writing with these qualities is to make our piece of writing understandable to our target.

Business organizations need and involve daily writing which are the documents written and used daily. These documents might not be the primary area of concern for the organization but these documents hold pivotal place in achieving the organization's aims and objectives. Ashton et al. (1999) describe these documents in The Work Skills in Britain Survey as "short documents" (e.g. short reports, letters or memos), and "long documents with accurate spelling and grammar" (e.g. long reports, manuals, articles or books). It is difficult yet significant to draft these documents. Every document that is written at a workplace is important in one way or other but its significance is context based. One needs to see the purpose for which it is written and the usefulness of the document. A detailed course outline of a course or a progress report written by a teacher for a student can be equally important in context of education as an official state document issued by the state authorities. To suffice communication through paper is important but a hard job. Anderson (1985), Beaufort (1999), Flower (1994), and MacKinnon (1993) in their research writings have discussed need, importance and stress involved in writing at the workplaces in the USA. They maintain that need for writing varies from workplace to workplace. It depends on the nature of the organization and the area it deals in but generally need for effective writing skills has increased during the last decade.

\subsection{Contextualized Teaching and Learning}

Skills in reading and writing are means of academic learning, but typically, these skills are taught independently of the discipline areas to which they must be applied. Despite the provision of substantial resources to providing developmental education courses that aim to bring the reading and writing skills of underprepared students to the college level (Boylan, Bliss, \& Bonham, 1997). Many students in college-credit courses exhibit continuing difficulties in relating these initial skills to the learning of subject matter (Perin \& Charron, 2006). A growing literature, particularly in the field of adolescent literacy, suggests that bringing basic skills and subject-area instruction closer together may be an explanation to this problem (Heller \& Greenleaf, 2007; Lee \& Spratley, 2010). One way to build this relationship is through contextualization, or the instruction of basic skills in the context of disciplinary topic areas. Tertiary developmental educators have recommended that pre-college educational skills teaching be directly related to the content of college-level courses (Simpson, Hynd, Nist, \& Burrell, 1997).

\subsection{Contextualization: Aim and Process}

Baker, Hope, and Karandjeff (2009) point out contextualization has been defined in many ways. One of those many definitions is proposed by Mazzeo, Rab, and Alssid (2003) "A diverse family of instructional strategies designed to more seamlessly link the learning of foundational skills and academic or occupational content by focusing teaching and learning squarely on concrete applications in a specific context" (pp. 3-4).

The aim of contextualization is to generate conditions for more valuable learning, expressed for example in higher grades and rates of retention in courses, and through succession to

\begin{tabular}{llll|l}
\hline JISR-MSSE & Volume 12 & Number 1 & January-June 2014 & 77
\end{tabular}


more advanced course work. Whether instruction is contextualized or integrated, the correlation of basic skills instruction to applications and life goals is reliable with constructivism, which places students' interests and needs at the center of education (Dowden, 2007). The theoretical literature suggests that both cognitive and affective methods bring about the expected improvement in learning outcomes. One of the most important tools in teaching a course is the text book or relevant material. Do ESP textbooks really exist? this is the fundamental question that Jones (1990) addresses. One of the basic problems he presents is that "ESP teachers find themselves in a situation where they are expected to produce a course that exactly matches the needs of a group of learners, but are expected to do so with no, or very limited, preparation time" (Jones, 1990).

\subsection{Role of English in Pakistan}

In a report, Dreams and Realities: Developing Countries and the English Language, Coleman (2011) has questioned over-simplistic theories about the practical value of English, particularly in developing countries. They have called for cautious discovery of the positive, negative and neutral roles that English plays in the developing world. In Pakistan, the role of English is intricate. It is the language of government, the military and higher education. It is the language of authority and the language of an influential class that has subjugated the country since independence. A characteristic of Pakistani diversity in English exists and has been illustrated by (Rahman, 2010b). Schools in Pakistan fall into four categories, the defining trait of which is the medium of instruction that is used:

- Elite private schools: The elite schools are reproduced on the British public school system; fees are very expensive; the medium of instruction is English.

- Schools run by the armed forces. They also use English as the medium of instruction.

- Public schools: Thay serve the multitude of the population. No fees are charged.

- Dini Madaris (madarasas): Run by religious organizations by the help of philanthropists (Coleman, 2010).

Shamim (2011) has explained the current language in education system in Pakistan as being one of "linguistic apartheid". Rahman (2004, p. 74) also, talks of "educational apartheid" between the English-medium elite schools and the Urdu-medium schools for the masses. At another place, Rahman (2010a) describes the situation in appalling terms:

“... by supporting English through a parallel system of elite schooling, Pakistan's ruling elite acts as an ally of the forces of globalisation at least as far as the hegemony of English is concerned. The major consequence of this policy is the weakening of local languages and the lowering of their status. This, in turn, opposes linguistic and cultural diversity, weakens the 'have-nots' even further and increases poverty by leaving the best-paid jobs in the hands of the international elite and the English-using elite of the peripheries" (p.30).

\subsection{Curriculum of Business Communications in Pakistan}

Business Communication is one of the compulsory courses taught at MBA level. Different universities may use some other terms for that but the core idea remains the same. Higher Education Commission (HEC, the monitoring body for universities in Pakistan) has laid

\begin{tabular}{l|llll}
78 & January-June 2014 & Volume 12 & Number 1 & JISR-MSSE
\end{tabular}


down some guidelines for teaching Business Communication at MBA level. After a critical study of these guide lines one point can be observed that HEC has set a curriculum for MBA students to improve their written communication. It has been a proven fact that every industry wants to see polished communication skills. Importance of communication skills can never be denied in any field of life. Different experts in Pakistani corporate world have expressed the need of these skills on more than one occasion. Some of them have been so blunt that they said that they do not need such graduate who cannot write even one letter. HEC is concerned about such issues and has been trying to develop communication skills. Current curriculum of Business Communication emphasizes on such writing skills that have been backbone to any industry. It highlights on skills like negotiation skills, letter writing, report writing and most importantly persuasive skills. Persuasion is a very difficult art and in every industry, at all levels this art is most needed. In fact this skill is required in our personal life for interpersonal personal communication as well. The course of Business Communication focuses on:

- To develop strong communication skills in the graduates so that they can standout in all walks of life.

- To make graduates prepared to fit in any position in any field, may be in the field of finance, marketing, economics, production, entrepreneurship, advertisement, human resource, administration or any other field.

- To give the graduates an edge over other people through their brilliant communication skills.

- To make them understand the ethical issues of communication and to develop a sensitivity in them regarding cross-cultural communication.

- To make the students anticipate ethical challenges in their corporate life ahead and to make them prepared for such issues so that they can handle them with confidence.

Problem that Business Communication has in Pakistan is that it has not been given its due importance. Everybody talks about its importance and regards this as lifeblood of every organization. Executives from every industry want to have people with strong communication skills but when it comes to practical contribution, there is hardly anyone who comes forth and tries resolving the issue. In private sector there are some people who are striving in this regard but in public sector universities there is still a lot to be done. Students, in their capacity, need to be well aware in this regard and should try to focus their energies towards attaining excellence.

\section{Research Methodology}

True experimental design is adopted for the research to explain the relationship between dependent and independent variables. Descriptive statistics is used to convert the textual data into numerical one in order to make it measurable and statistically provable. ANOVA is used to draw inferences from the data obtained.

\subsection{Justification of the Selection of the Research Design}

In context of this study the dependent variables are: Students' writing skills, thinking skills and appropriate ethical and social development and independent variable is contextualized text. It is proved that only independent variable never has sole effect on the dependent

\begin{tabular}{llll|l}
\hline JISR-MSSE & Volume 12 & Number 1 & January-June 2014 & 79
\end{tabular}


variables. Rather involvement of attribute variables must also be documented to circumvent artificial simplicity in the experiment. Artificial simplicity hampers the extent of true effects of the treatment on the dependent variable. Socioeconomic condition of the subjects is the attribute variable in the study. The factorial design studies the impact of attribute variable(s) on dependent variable along with independent variables, the same design was selected for the study. Social sciences researchers often use factorial designs to assess the effects of educational methods, whilst taking into account the influence of socio-economic factors and background (Ary, 1990). Second, the research required study of effects of more than one variable, manipulated simultaneously, on dependent variable; factorial design is most suitable for the purpose. Third, along with the reasons stated, the factorial design also increases generalizability of the research; same was used for the study.

\subsection{Research Question}

- Does teaching Business Writing through contextualized text develop writing skills in the learners at tertiary level?

\subsection{Hypotheses}

- Ho: Contextualized text does not facilitate learners in learning writing skills of English for business purposes than that of non-contextualized text.

- $\mathrm{H}_{1}$ : Contextualized text facilitates learners in learning writing skills of English for business purposes than that of non-contextualized text.

\subsection{Population and Target Population}

The accessible population for this study is all undergraduate students of public Sector Business Schools of Karachi.

The target population of the study is all undergraduate students of public sector business schools of Pakistan. One public sector business school of Karachi was randomly selected for the study using Simple Random Sampling technique from which 80 students were distributed in two groups; control and experimental groups with 40 students in each group. Karachi is a metropolitan city. People come from diverse ethnic backgrounds live in the city. For their academic needs they study in public sector universities; where merit rather than fee affordability is the criterion for admission. For this reason the researcher decided to make public sector business schools of Karachi as his sample through random selection.

\subsection{Sampling Technique and Procedure}

The adopted sampling technique is probability sampling. The researcher adopted sampling procedure the steps given below:

A university is randomly out of four public sector business schools in Karachi. In second step the concerned authority was contacted for the permission and administrative support in order to conduct study effectively. The university management allowed to conduct the study and offered their full support for the purpose of educational research. The concerned authorities

\begin{tabular}{l|llll}
\hline 80 & January-June 2014 & Volume 12 & Number 1 & JISR-MSSE
\end{tabular}


facilitated the random selection of the students from the list of all enrolled students in the course of Business Communication. The researcher selected randomly the students from the list in the presence of the university management. The researcher also randomized the selected sample for the controlled and experimental groups in the same way. Randomization is the process to use chance procedure in assigning the subjects to the group. No criterion was made in assigning subjects to the control or experimental groups. The students were not informed about the groups whether they are part of controlled or experimental. This was done to avoid Hawthorne Effect. "The Hawthorne Effect is the tendency, particularly in social experiments, for people to modify their behaviour because they know they are being studied, and so to distort (usually unwittingly) the research findings"(Payne, 2004).

\subsection{Research Instruments}

The research instruments that have been used for the study are:

Contextualized Text: Contextualized text was developed by the researcher and got it approved by three subject specialists; to make the text valid. Necessary changes were made in the text based on the comments of the subject specialists and pilot testing. Achievement Test: At the end of the teaching of each group, one achievement test was administered to measure the effects of the contextualized text on their writing skills i.e. once in the last class of control group teaching process and second time same test was administered in the last class of experimental group teaching process. This achievement test had 8 questions in total with 7 questions containing different contextualized situations and one question of MCQs (Multiple choice questions). Maximum marks of the test were 100 and the students had 3 hours to finish it. The concerned authorities of the university facilitated the researcher for random selection of the students from the list of all enrolled students in the course of Business Communication. The researcher selected randomly the students from the list in the presence of the university management. The researcher also randomized the selected sample for the controlled and experimental groups in the same way. Randomization is the process to use chance procedure in assigning the subjects to the group. No criterion was made by the researcher in assigning subjects to the control or experimental groups. The students were not informed about the groups whether they are part of controlled or experimental. This was done to avoid Hawthorne Effect.

\subsection{Variables and Justification}

The researcher studied the relationship of the variables given below:

- Contextualized text.

- Students' writing skills.

- Socioeconomic status of the students.

\subsection{Operationalization of the Variables}

Contextualized text refers to the text used for teaching a particular subject in accordance to the local needs and cognition level of the learners. Any subject can be taught with two different materials. Text books written by foreign authors in foreign context and text locally produced in local context. Contextualization is teaching skills with direct reference to real world events 
and practices (Berns \& Erickson, 2011). In the study, contextualized text is an independent variable. In context of the study text was developed which was in accordance with local needs of the students and included local examples and case studies in contrast with regular foreign authored text that has been in use for teaching writing skills for English for specific purposes. For the study, contextualized text was operationalized under the three the heads:

Familiar situation; Known vocabulary; Learners' interest

To teach students how to write for the workplace and other professional contexts, technical writing teachers often assign writing tasks that reflect real-life communication contexts, a teaching approach that is grounded in the field's contextualized understanding of genre (Hanm, 2008). In order to develop a contextualized text for writing of English for specific purposes first thing that was taken into consideration was familiar situation. The text included situations that were familiar to the learners as compared to foreign authored text. The idea was to offer learners such examples that were easy to understand and belong to their own local context. Case studies that were included in the text were derived from local industry and correspondence in the local market to make it familiar for the learners.

Writing skills is one of the dependent variables in the study. Treatment in the form of contextualized text was administered to the subjects of experimental group and the impact of this treatment was observed on different independent variables. Writing skills is a basic skill of English language. As in the study, writing skills for English for specific purposes is the area of concern, writing skills in English for business purposes was taken as dependent variable. Writing is not a natural activity, so explicit instructions are required for learning this skill (Aronoff \& Miller, 2007). Writing skills for business have different aspects that are different than writing for academic purposes. The researcher has set certain criteria to assess learners' writing skills. These criteria are: Comprehensiveness, brevity, precision, thoughtfulness, courtesy, accuracy.

Socioeconomic status of the students has been taken as an attribute variable in the study. The factors that are usually considered in establishing SES are income, occupation, education, neighborhood, and political power. Subjects of the study were selected randomly but their socioeconomic status could not be controlled. The researcher did not want to create artificial simplicity by avoiding this variable. This problem was catered by adopting factorial design so that the impact of attribute variable could also be measured and true results could be found after the experiment.

\subsection{Piloting of the Contextualized Text}

All the research instruments were piloted on population like subjects in a business school other than the one included in the study. These subjects were randomly selected from a randomly selected business school and necessary modifications were made to enhance its validity. The number of subjects for piloting was 30 . 


\subsection{Ethical Issues}

Special care has been taken to keep honesty in producing the new knowledge. Legal permissions from the concerned authorities of institutions were taken in advance. Consent of the participants was also taken. The subjects were free to leave the experiment at any point of time. Confidentiality of the data was affirmed. Names of teachers, subjects or their institutions have not been mentioned so that the data cannot be used for any other purpose against the respondents or their organizations. Prior appointments were taken before reaching any respondent and whole purpose of the data was explained to them so that they might feel comfortable and might give consent in this regard.

\section{Analysis of Data}

Figure 1. Achievement test scores of control group

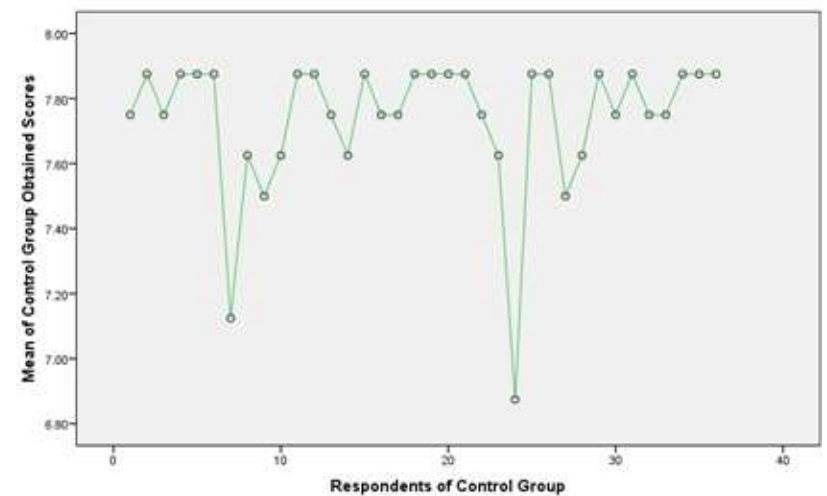

Figure 1 represents respondents of Control Group on X axis and mean of obtained scores of the respondents of Control Group on Y axis. Total number of respondents shown is 36. Mean of lowest score is 6.9. Maximum respondents obtained mean score between 7.7 and 7.9. The graph shows consistency of the scores as well as variability of the respondents. It depicts reliability and consistency of the tool. 
Figure 2. Achievement Test scores of experimental group

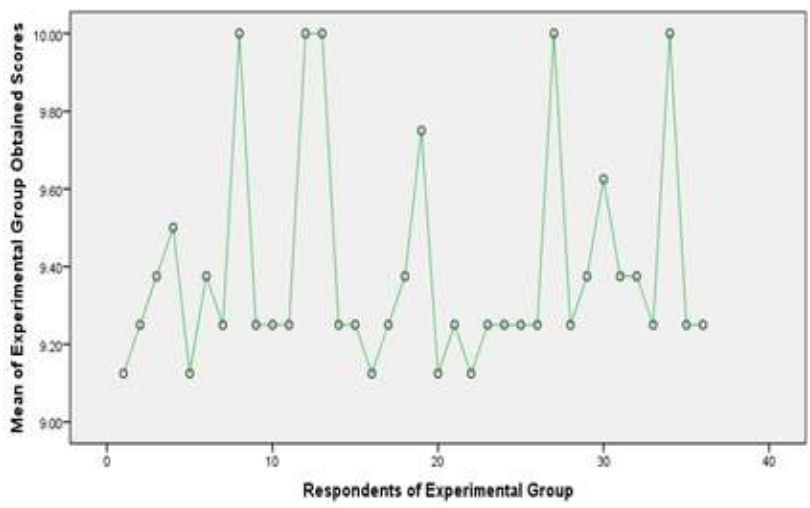

Figure 2 shows respondents of Experimental Group on $\mathrm{X}$ axis and mean of obtained scores of the respondents of the Experimental Group on Y axis. Lowest mean score is 9.19 while highest is 10. Data falls consistently between 9.23 and 9.5 . This depicts consistency of the data. The result represents reliability and consistency of the tool.

\subsection{Comparison of Figure 1 and 2}

Comparison of both the graphs shown in figures 1 and 2 represents that tool; that was achievement test, was reliable as the data is consistent. Variation in mean scores has also been found which depicts understanding of the subjects regarding the course content taught to them during the experiment. Maximum data, in case of Control Group (fig.1) falls between 7.7 and 7.9 while for Experimental Group (fig. 2) it falls between 9.23 and 9.5. Subjects of the Experimental Group managed to score higher than Control Group which represents their understanding of the concepts, ability of reading comprehension and thinking ability.

Table 1

Table of Significance

Correlations

\begin{tabular}{llll}
\hline & & $\begin{array}{l}\text { Use of contextualized } \\
\text { text for teaching } \\
\text { Business Writing }\end{array}$ & $\begin{array}{l}\text { Means of obtained } \\
\text { scores in achievement } \\
\text { test }\end{array}$ \\
\hline $\begin{array}{llll}\text { Use of contextualized } \\
\text { text for teaching }\end{array}$ & $\begin{array}{l}\text { Pearson Correlation } \\
\text { Business Writing }\end{array}$ & 1 & $0.958^{* *}$ \\
Sig. (2 tailed) & $\mathrm{N}$ & 72 & 0.000 \\
\hline $\begin{array}{l}\text { Mean of obtained } \\
\text { scores in }\end{array}$ & Pearson Correlation & $0.958^{* *}$ & 72 \\
achievement test & Sig. (2 tailed) & 0.000 & 1 \\
\hline
\end{tabular}

** Correlation is significant at the 0.01 level (2-tailed) 
Table 1 presents the result of test of significance. Pearson correlation was used to find out the relationship between variables i.e. use of contextualized text and mean of obtained scores of both control and experimental groups. The table demonstrates positive relationship between the two variables shown in the table by the value 0.958 . The level of significance is 0.01 . Pvalue in the table is 0.00 . The estimated co-efficient of correlation is 0.958 which signifies existence of strong relationship between contextualized text and achievement of the students. Level of significance i.e. 0.01 in the table illustrates strong significance of the test. P-value in the table i.e. 0.00 shows that null hypothesis is rejected leading to the conclusion that strong positive correlation between the variables exists.

Table 2

Table of Significance

Correlations

\begin{tabular}{llll}
\hline & & $\begin{array}{l}\text { Mean of obtained } \\
\text { scores in achievement } \\
\text { test }\end{array}$ & $\begin{array}{l}\text { Socioeconomic } \\
\text { status of the students }\end{array}$ \\
\hline Means of obtained & Pearson Correlation & 1 & 0.030 \\
scores in achievement & Sig. (2 tailed) & 72 & 0.805 \\
test & $\mathrm{N}$ & 72 \\
\hline Socioeconomic & Pearson Correlation & 0.030 & 1 \\
status of the students & Sig. (2 tailed) & 0.805 & 72 \\
& $\mathrm{~N}$ & 72 & \\
\hline
\end{tabular}

Table 2 shows relationship between Socio-economic Status (SES) of the students and their achievement in the test in terms of scores. Pearson correlation was used for the test of significance. Co-efficient of correlation in the table is 0.030 . This value represents weak relationship between the two variables. P-value is 0.805 which is greater than 0.05 (thresh hold value) and depicts that there is no relationship between the variables. It leads to the logical analysis that the two variables that are SES and Students' achievement in the test do not have any relationship. The achievement of the students in the test does not vary because of their socio-economic status.

\subsection{Hypothesis testing for Writing Skills: Analysis of Variance}

$\mathrm{H}_{1}$ : Contextualized text facilitates learners in learning writing skills of English for business purposes than that of non-contextualized text.

Ho: Contextualized text does not facilitate learners in learning writing skills of English for business purposes than that of non-contextualized text.

Table 3

ANOVA

Mean of obtained scores in achievement test

\begin{tabular}{llllll}
\hline & $\begin{array}{l}\text { Sum of } \\
\text { Squares }\end{array}$ & df & Mean Square & F & Sig. \\
\hline Between Groups & 48.964 & 1 & 48.964 & 782.566 & 0.000 \\
Within Groups & 4.380 & 70 & & & \\
Total & 53.344 & 71 & 0.063 & & \\
\hline
\end{tabular}


Writing Skills of the students were tested in the whole achievement test. Table 3 is Analysis of Variance (ANOVA). Column 1 of the table shows groups. Column 2 contains sum of squares. Column 3 represents degree of freedom. Column 4 shows mean of square. Column 5 contains F ratio and column 6 depicts significance of the test. Significance Value is 0.00 which depicts that null hypothesis is rejected. F ratio obtained i.e. 782.566 (highlighted in the table) is also significant which suggests that the results of the findings are significantly valid. The table shows difference between groups is higher than the difference within group and hence the obtained $\mathrm{F}$ ratio explains the mean of experimental group is greater than the mean of control group. Therefore, the test shows that the students taught through contextualized text improved their writing skills significantly than those taught through non-contextualized text.

Table 4

Effect of SES on Writing Skills with the Treatment: Two way Analysis of Variance (Tests of Between-Subjects Effects)

\begin{tabular}{llllll} 
Dependent Variable: Mean of obtained scores in achievement test \\
\hline Source & $\begin{array}{l}\text { Type I Sum } \\
\text { of Squares }\end{array}$ & df & Mean Square & F & Sig. \\
\hline Corrected Model & $49.040 \mathrm{a}$ & 5 & 9.808 & 150.423 & 0.000 \\
Intercept & 5280.922 & 1 & 5280.922 & 80992.248 & 0.000 \\
Treatment & 48.964 & 1 & 48.964 & 750.946 & 0.000 \\
SES & 0.054 & 2 & 0.27 & 0.413 & 0.664 \\
Treatment*SES & 0.023 & 2 & 0.011 & 0.173 & 0.841 \\
Error & 4.303 & 66 & 0.065 & & \\
Total & 5334.266 & 72 & & & \\
Corrected Total & 53.344 & 71 & &
\end{tabular}

Table 4 presents the result of Test of between Subjects Effects for 2 Way ANOVA. Column 1 of the table is source. Column 2 shows sum of squares. Column 3 represents degree of freedom. Column 4 depicts mean square. Column 5 of the table gives values of $F$ Ratio and column 6 shows value of significance. The table illustrates that treatment given to the group contributes significantly in students' social and ethical development independently as F ratio shows 750.946 with significance value 0.000 which is less than threshold value of 0.05 . This indicates rejection of Ho and acceptance of H1. F ratio obtained for SES is 0.413 and its value of significance is 0.664 . When combined effect of independent and attribute variables i.e. treatment and students' socioeconomic status was tested, the obtained values (F ratio: 0.173; Value of Significance: 0.841) show that SES does not have any effect with the treatment in the learning of the subjects. It suggests that contextualized teaching is the only factor that impacts students' writing skills.

\section{Discussion}

In modern age English language has taken central importance and has become focal point for all non-native countries. There have been so many researches around the world regarding teaching of English to improve the quality of teaching and inculcating the language skills among the students more effectively. To contribute to larger knowledge body, the researcher of this study has also added his share through empirical evidences. As English is a language 
that is comprised of four skills i.e. Listening, Reading, Speaking and Writing, the language is to be taught skill based. Focus of the study is writing of English for specific purposes and impact of contextualized text on students' learning was analyzed. During teaching through non-contextualized text, the researcher observed anxiety and inability of students in either grasping the concepts or maintaining their interest in the class only because of text used for teaching. This became one of the reasons for selection of the area of study. As first step, researcher analyzed the need of Pakistani industry regarding communication skills. The study showed a grave need of contextualization, as practices in the Pakistani industry are different from what the students are taught in foreign authored books.

The related literature reviewed by the researcher also proved the significance of the problem of the study. To narrow down a felt problem or a vague notion about what one wants to investigate into a researchable problem, population and variables have to be identified. Therefore the researcher selected Contextualized text as independent variable while Students' writing skills dependent variable. Socioeconomic status (SES) of the students was taken as attribute variable. To study the causal relationship among these variables the researcher selected the most appropriate population which was students studying the course of Business Communication at tertiary level in Pakistan. From the whole population the researcher selected the accessible population in order to maintain practicality and access till the end of the study which was all the public sector universities of Karachi. To make the sample more representative of the target population probability sampling procedure was adopted throughout the sample selection and group making. Simple random sampling technique was used at every step. "The basic characteristic of simple random sampling is that all members of the population have an equal and independent chance of being included in the sample. That is, for every pair of elements $X$ and $Y, X$ 's chance of being selected equals $Y$ 's chance, in the selection of $X$ in no way affects Y's probability of selection"(Gay, 2005). For experimental study, at least two groups were required therefore a single public sector institution was selected randomly without any bias or pre-set criterion. Subjects were selected who were registered in the course of Business Communication at undergraduate level. Two groups were made for the experiment namely control group and experimental group. A neutral venue was selected to control extraneous variables that might affect the experiment.

Duration of the class and total teaching hours were in accordance with the HEC recommendations. Control group was taught first to avoid the Hawthorne effect. Contextualized text was developed by the researcher and expert opinion was taken from three subject specialists. The text was piloted then on sample like population and necessary changes were made as a result of pilot testing. Achievement test used as post-test was also piloted on the same population at the end of teaching process.

After instrument development and pilot testing, the researcher selected the most suitable research design after thorough study of the research methodologies which was Simple Factorial Design; one of True Experimental Designs. Rationale of selecting this design was to take into account variables other than variables of interest. According to Ary et al. (1990) "a factorial design is one in which two or more variables are manipulated simultaneously in order to study the independent effect of each variable on the dependent variable as well as the effects due to interaction among the several variables." Eighty students were randomly selected as sample for the study from the population, and then randomized forty in each group; control and experimental group. Control group was taught by foreign authored non-

\begin{tabular}{llll|l}
\hline JISR-MSSE & Volume 12 & Number 1 & January-June 2014 & 87
\end{tabular} 
contextualized text used in regular teaching practice in the universities and experimental group was taught by contextualized text. Students' learning was analyzed through an achievement test.

Contextualized text is the independent variable of the study. The impact of the independent variable was observed on the dependent variables - Students' writing skills. In the study, socioeconomic status of the students is not the variable of interest for the researcher but it is an attribute variable that might affect the findings of the study. Therefore the researcher took it into account to make findings of the study more valid and credible. The results of the data analysis show existence of strong causal relationship between contextualized text and achievement of the students. The tests also suggest the two variables that are SES (SocioEconomic Status) and Students' achievement in the test do not have any relationship. The achievement of the students in the test does not vary because of their socio-economic status. They also represent that SES does not have any effect with the treatment in the learning of the subjects. They imply that contextualized teaching is the only factor that impacts students' learning of writing of English for specific/business purposes.

In the light of analyses it is evident that use of contextualized text impacts students' learning positively and creates opportunities of not only swift learning but also applying the concepts on real-time problems.

\section{Findings}

Findings of the study are based on the analysis that was done on the data found as a result of the experiment. Statistical data analysis was done through SPSS 18. First thing to find out was reliability of the tool. This was tested and the tool i.e. contextualized text was found to be reliable and consistent. The test has been discussed in figures 1 and 2 show consistency of the tool. This is a comment on the validity of the text used in the classroom for teaching. Relationship between contextualized text and students' learning was tested and the findings suggest that a strong positive relationship between these variables exists. This finding suggests that students' learning depends significantly on the selection of text used for teaching. If a non-contextualized text is used for teaching writing skills for business purposes, they tend to achieve less learning as compared to those who are taught through contextualized text. Writing skill is one of the most difficult skills in the language and for teaching this skill the most important and powerful tool that a teacher might have is the text. Therefore teacher needs to select the text intelligently in order to facilitate students' learning and interest.

Tables 3 and 4 show that the students taught through contextualized text improved their writing skills significantly than those taught through non-contextualized text. The tables also suggest that SES does not have any effect with the treatment in the learning of the subjects. It suggests that contextualized teaching is the only factor that impacts students' learning of writing skills. This leads to the conclusion that socioeconomic status, along with independent variable does not impact dependent variables significantly.

This study was an attempt of working on contextualized text for English Language in general and English for business purposes in particular. This experimental study was conducted as an effort to produce some empirical evidences if idea of contextualization workable in Pakistani setting and to what extent. It was also an endeavor to encourage scholars and 
English Language Teachers to go for contextualization in the field of ELT to make learning more effective and quick for the learners. Statistically tested data supports the idea that introduction of contextualized text develops students' writing skills quicker and more effectively than that of foreign authored text. This has been need of the time in Pakistan especially for curriculum developers and academic administrators to now change gear and start adopting newer and better methods and techniques for teaching. It was also an attempt to provide tested and authentic literature in the field of contextualized teaching learning especially in local context so that the researchers of education and applied linguistics can make us of it for further research. The study tried to also find out the hindrances that teachers face in developing and executing contextualized text in their classes. This document can be used as a reference for those who are a part of academic administration to create willingness among them for adopting a new approach of teaching in Pakistan. Globally the idea of contextualized teaching learning is not absolutely new but in a developing country like Pakistan where curricula are hardly revised, it is comparatively new study that has been conducted and presented with empirical evidences.

\section{Recommendations}

Keeping in view the findings of the study the following recommendations can be put forth:

- Students of English Language at tertiary level should be given an opportunity for contextualized learning through introducing contextualized text.

- More orientation and training on skill based teaching is required from the government to be offered. There have been some efforts by some private agencies like EDLINKS more of such efforts are needed at tertiary level as well.

- Students of English Language at tertiary level should be given an opportunity for contextualized learning through introducing contextualized text.

- Academic administrators should be trained and authorized to not only handle new ideas but also giving room for novice approaches like CTL.

- Skill based teaching especially for English Language Teaching should be made mandatory.

- More orientation and training on skill based teaching is required from the government to be offered. There have been some efforts by some private agencies like EDLINKS more of such efforts are needed at tertiary level as well.

- In-house training sessions should also be conducted by all the universities as prerequisite by HEC-Pakistan in the area of CTL.

- All faculty members in public sector universities should be compelled to discuss the objectives of skilled based teaching.

- Incentives should be announced and given to all faculty members who initiate the idea of Contextualized Teaching Learning so that this can be encouraged.

- It should be compelled by the HEC to all universities to submit an academic audit report in general and skill based teaching through CTL in the field of ELT in particular failing of which may lead to a penalty to the overall ranking of the university. 


\section{References}

Anderson, P. V. (1985). What survey research tells us about writing at work. In Lodell \& D. Goswami (Eds) Writing in Nonacademic Settings, New York:G uil-ford.

Anokye, A. D. (2008). Teaching writing teachers to teach writing. In Friedrich (Ed.), Teaching academic writing (pp. 59-72). New York: Continuum.

Aronoff, M., \&, Rees-Miller, J., 2007. The handbook of linguistics. Oxford: Blackwell

Ary, D. (1990). Introduction to Research in Education. Forth Edition. New York: Holt, Rhinehart and Winston.

Ashton, D., Davies, B., Felstead, A.\& Green, F. (1999) Work Skills in Britain. ESRC Centre on Skills, Knowledge and Organisational Performance.

Baker, E. D., Hope, L., \& Karandjeff, K. (2009). Contextualized teaching and learning: A faculty primer. Sacramento, CA: The Research and Planning Group for California Community Colleges, Center for Student Success. Retrieved from http://www.careerladdersproject.org/docs/CTL.pdf

Berns, R. G., \& Erickson, P. M. (2001). Contextual teaching and learning: Preparing students for the new economy, Louisville, KY: University of Louisville, National Research Center for Career and Technical Education.

Brown, H. D. (2001). Teaching by principles: An interactive approach to language pedagogy 2nd ed. White Plains, N.Y.; Longman.

Beaufort, A. (1998). Transferring writing knowledge to the workplace. Are we on track? In M.

S. Garay \& S. A. Bernhardt (Eds) Expanding Literacies: English Teaching and the New Workplace Albany: State University of New York Press.

Boylan, H. R., Bliss, L. B., \& Bonham, B. S. (1997). Program components and their relationship to student performance. Journal of Developmental Education, 20(3), 2 9.

Celce-Murcia, M. (2001). Teaching English as a second or foreign language (3rd ed.). Boston: Heinle \& Heinle.

Coleman. H. (2010). Teaching and learning in Pakistan: The role of language in education. Islamabad: British Council.

Coleman, H. (2011). Dreams and Realities: Developing Countries and the English Language. London: British Council. Retrived from http://www.teachingenglish.org.uk/transform/books/dreams-realities-developing countries english- language

Dolch, E.W. (1942). Better Spelling. Champagne, Illinois: The Garrard Press.

\begin{tabular}{l|llll}
\hline 90 & January-June 2014 & Volume 12 & Number 1
\end{tabular}


Cruse, Alan D. (2000). Meaning in Language: An Introduction to Semantics and Pragmatics. United States: Oxford University Press Inc.

Dowden, T. (2007). Relevant, challenging, integrative and exploratory curriculum design: Perspectives from theory and practice for middle level schooling in Australia. Australian Educational Researcher, 34(2), 51-71.

Dudley-Evans, T., \& St John, M. (1998). Developments in ESP: A multi-disciplinary approach. Cambridge: Cambridge University Press.

Flower, L. (1994). The Construction of Negotiated Meaning. A Social Cognitive Theory of Writing (Carbondale, IL, Southern Illinois University Press.

Heller, R., \& Greenleaf, C. L. (2007). Literacy instruction in the content areas: Getting to the core of middle and high school improvement. Washington, DC: Alliance for Excellent Education.

Hutchinson, T., \& Waters, A. (1987). English for Specific Purposes: A learning-centered approach. Cambridge: Cambridge University Press.

Gay, L. R. (1987). Educational Research Competencies for Analysis and Application,Selection of Measuring Instruments, 3rd ed.

Jones, G. (1990). ESP textbooks: Do they really exist? English for Specific Purposes, 9, 8993.

Kameda, N. (2001). The inpublication of language style in busniess communication focus on English vessus japanese Corporate Communications, 6(3), 144-149.

Lee, C. D., \& Spratley, A. (2010). Reading in the disciplines: The challenges of adolescent literacy. New York, NY: Carnegie Corporation of New York's Councilon Advancing Adolescent Literacy.

Mackinnon, J. (1993) Becoming a rhetor: developing writing ability in a mature, writingintensive organization. In R. SPILKA, (ed) Writing in the Workplace: New Research Perspectives, Illinois, Southern Illinois Press.

Mazzeo, C., Rab, S. Y., \& Alssid, J. L. (2003). Building bridges to college and careers: Contextualized basic skills programs at community colleges. Brooklyn, NY: Workforce Strategy Center.

McDonough, J., \& Shaw, C. (2003). Materials and methods in ELT: A teacher's guide (2nd ed.). Malden, MA: Blackwell Pub.

McKee, P. (1939). Language in the Elementary School. Cambridge, Massachusetts, USA: The Riverside Press.

\begin{tabular}{lll|l}
\hline JISR-MSSE & Volume 12 & Number 1 & January-June 2014
\end{tabular}


Morgan, C. M. (2001). (M) other tongue: A selected annotated bibliography of world "Englishes." Collection Building, 20(2), 73-80.

Perin, D., \& Charron, K. (2006). Lights just click on every day. In T. Bailey \& V. S. Morest (Eds.), Defending the community college equity agenda (pp. 155-194). Baltimore, MD: Johns Hopkins University Press.

Payne \& Payne, (2004). Key Concepts in Social Research, Sage Research Methods, Online ISBN: 9781849209397,http://srmo.sagepub.com/view/key-concepts-in-social research/n22.xml

Peyton, J.K. (1993). Dialogue journals: Interactive writing to develop language and literacy. ERIC Digest. Washington, DC: National Center for ESL Literacy Education. (EDRS No. ED 354 789)

Quattrini, J. A. (1985). Brushing Up Your Writing Skills. 215 Park Avenue South, New York, N.Y. 10003: Arco Publishing, Inc.

Rahman, T. (2010a). Language Policy, Identity and Religion: Aspects of the Civilisation of the Muslims of Pakistan and North India. Islamabad: Quaid-i-Azam University.

Rivers, W. M. (1968). Teaching foreign-language skills. Chicago: University of Chicago Press.

Richards, J. C., \& Renandya, W. A. (2002). Methodology in language teaching: An anthology of current practice. New York: Cambridge University Press.

Shamim, F. 2011. English as the language for development in Pakistan: Issues, challenges and possible solutions.

Shidle, N. (1965). The Art of Successful Communication. USA: McGraw-Hill, Inc.

Simpson, M. L., Hynd, C. R., Nist, S. L., \& Burrell, K. I. (1997). College academic assistance programs and practices. Educational Psychology Review, 9(1), 39-87.

Yusuf, M. (2007). Effects of Skill-Oriented Language Teaching Strategy on the Performance of Non-Native Higher Education English Students: A doctoral dissertation.

Zhu, W. (2002). A rationale and guide for integrating writing into English language instruction. In C. M. Feyton (Ed.), Teaching ESL/EFL with the Internet(pp. 94-122). Upper Saddle River, NJ: Merrill Prentice-Hall. 